\title{
Author Spotlight: Giovanna Impellizzeri
}

\section{Giovanna Impellizzeri ${ }^{1}$}

Accepted: 23 November 2020 / Published online: 12 January 2021

(c) The Author(s), under exclusive licence to Springer Science+Business Media, LLC part of Springer Nature 2021

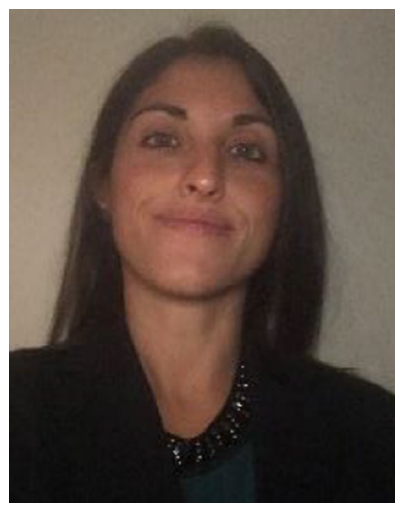

diagnostic and therapeutic endoscopy of the upper and lower gastrointestinal tract.

Publisher's Note Springer Nature remains neutral with regard to jurisdictional claims in published maps and institutional affiliations.

Giovanna Impellizzeri is a MD, graduated at the University of Catania in 2015, and a senior registrar in Gastroenterology at the Sant'Orsola Hospital, Bologna. She is interested in the study of digestive and liver diseases and moreover in

Giovanna Impellizzeri

impellizzerigiovanna@gmail.com

1 University of Bologna, Bologna, Italy 